found to weigh I IO grains, and to measure one inch and one-eighth in the long, and half an inch in the transverse diameter. On May 22nd, he was discharged cured, never having had a bad symptom.

CASE XV. - Thomas Hennessy, aged I7, bricklayer's labourer, came under care on August I 2th, I 868. Three weeks previously he first felt what he called a bone in his left knee-joint. It gave him great pain. He sometimes fell, and could not rise or walk until the cartilage was dislodged from its position. On August 2 Ist, the cartilage being fixed at the inner and lowest part of the joint, it was removed from the joint, and embedded in the cellular tissue in the ordinary manner. The treatment was as usual. On September 9 th, he had had no bad symptom. The cartilage was excised; it was of the size and shape of a hazel-nut. On September I4th, there had been slight suppuration in the cellular tract since the removal of the cartilage; otherwise he was quite well. On the I 6 th, he was discharged cured.

CASE XVI.-Mary Hayman, aged 22, servant, was operated upon by subcutaneous incision by $\mathrm{Mr}$. Whipple on December 2nd, I 868, and discharged cure 1 ( )n December 22nd. There is no history of this case; but it is evident that the result was perfect, not only from the statement of her cure in the hospital admission-book, but also from the fact that she was only twenty days under treatment.

CASE XVII. - F. Johns, aged 20 , had a loose cartilage in the knee joint, and was operated upon by Mr. Fox by subcutaneous incision in the South Devon and East Cornwall Hospital. I can find no record of this case ; but the cure was complete without accident, and I am enabled to show you the cartilage with an inscription referring to the case.

CASE XVIII.-John Hocking, aged $5 \mathrm{I}$, miner, came under treatment May 25th, 1870. A loose cartilage was very evident in the right knee-joint. Fourteen years ago, he received a severe blow on his knee, and ever since had felt the foreign body in the joint. It gave him little annoyance until a fortnight ago, when the joint became distended with synovia; and ever since that time he had frequently fallen while walking, from the sudden movement of the cartilage.

Operation, May 25th. - The cartilage was with great difficulty fixed on the outer side of the joint. I was obliged to incise the capsule of the joint most freely; and by patient long continued manipulation I lifted the cartilage from the joint into its cellular bed. I fixed it with a firm pad, adhesive plaster, and bandage, in the usual way; and placed the limb on a straight splint, at an angle of forty-five degrees. On June 8th, he hád had no pain or swelling. The cartilage was excised. On July Ist, he was discharged cured. Some delay in his cure arose from a slight suppuration which occurred in the wound from which the cartilage was removed.

CASE XIX. - G. Gorfett, aged 38 , ironfounder, was operated on September Ioth, I869, when the subcutaneous operation for loose cartilage in the knee-joint was performed by Mr. Whipple at the hospital. On September 29th, he was discharged cured.

CASE XX. - Wm. Teale, aged 52, sailor, was admitted into the South Devon and East Cornwall Hospital February 4th, 1870, with loose cartilage in the right knee-joint, under the care of $\mathrm{Mr}$. C. Whipple, who operated upon him by subcutaneous incision on February 6th. Ho was discharged cured on March 23rd. He had no bad symptom during the treatment.

CASE XXI. - Wm. Bennett, farm-labourer, Landulph, was operated upon by subcutaneous incision by Mr. Kempthorne. He was treated as before described, and was cured without the occurrence of any bad symptom.

CASES XXII, XXIII, and XXIV, were operated upon by Mr. W. Swain, of the Albert Hospital. They were all operated upon by subcutaneous incision, were treated on the plan before indicated, and all recovered without a bad symptom.

Since writing the above paper, I find a case reported in our JOURNAL for July 29th, 187I, by Mr. Alford, of the Taunton and Somerset Hospital. There were two loose cartilages in the right knee-joint. On May Ist, they were lodged in the cellular tissue of the thigh. On the 2oth, they were excised; and on June 2oth the patient left the hospital cured.

I have now given you a short report of twenty-four consecutive and unselected cases, cured, without anxiety or accident, by subcutaneous incision. Surely immense responsibility must henceforth attach to any one who ventures to incur the risks of direct or valvular incision. most sincerely hope that these splendid results may carry conviction to all your minds.

When Mr. Syme had for the first time performed the operation which I advocate, he was so satisfied with it, that he said to his class, "When the safety and facility of this procedure are contrasted with the danger of excision and the irksome confinement to bed of several weeks' duration, which is requisite for accomplishing the process of fix. ture, I think that there can be no doubt that the profession is greatly indebted to $\mathrm{Mr}$. Square for perfecting the subcutaneous operation and rendering it available for all cases of the disease."

There are several varieties of loose cartilages. I am acquainted with five; and probably there are more. One variety originates in masses of lymph which have been effused by the inflammatory process. They may be termed fibrinous exudations. The second is a mere precipitate from a morbid synovial secretion. Rokitansky says that these loose bodies are often laminated. The third variety is described by Dr. Rohert Adams, who calls them "addimentary bones". They are formed around the cavities of joints, or upon their articulations, in the course of chronic rheumatic arthritis. They often separate from their attachments, and become loose in the cavities of joints.

These three varieties have little surgical significance; but the two others are in this respect of more importance. The fourth variety is produced by the abnormal or morbid growth of the fine fringes of the synovial membrane. Kölliker states that these processes increase in size, solidify, and become detached from the vascular folds. These loose cartilages are composed principally of hyaline cartilage, and present calcified spots, generally about their centre. The fifth variety is of all the most important to surgeons, as it furnishes the majority of cases for operation. I here show you specimens from patients whose cases are recorded in this paper. Their surface on one side is smooth and shining, having a yellowish waxy aspect. On the other side, they often have a bony appearance and structure. The yellowish waxy portions consist of true articular cartilage, and the opposite side of true bone, as demonstrated by the microscope.

In the short paper which I published in I86I, I said " that a large proportion of these cases are the result of local injury-that, by accidental violence, small or large portions of the articular structures are detached." In the fourth volume of the St. Bartholomez's Hospital Reports is an excellent paper by Mr. Marsh, referring to this variety of loose cartilage. He says : "The forms of disease to which I wish to draw especial attention here is one that has been referred to by several surgical writers, although its occurrence has never, I think, been generally acknowledged. It is that which results from the breaking off or shedding into the cavity of a joint of a portion of the proper articular cartilages, together with a layer, more or less substantial, of the subjacent bone."

In the sixth volume of the St. Bartholomew's Hospital Reports, Mr. Paget has a paper on the Production of Loose Cartilages in Joints, in which he expresses his opinion, based upon facts observed by himself, that this group of loose cartilages has its origin in violence resulting in what he calls quiet necrosis. He says that these bodies are sequestra exfoliated after necrosis of injured portions of cartilage, and exfoliated without acute inflammation. In a note, Mr. Paget remarks that the late $\mathrm{Mr}$. Teale published a like explanation of the occurrence of this form of loose cartilage in the thirty-ninth volume of the Medico-Chirurgical Transactions.

\section{DESCRIPTION OF A NEW STRICTURE-DILATOR.*}

By BERKELEY HILL, F.R.C.S., Surgeon to University College and the Lock Hospitals.

THE dilator that I venture to show you operates on the principle of Perrève's, Holt's, and Richardson's. The two halves of a split sound, which in juxtaposition equal the calibre of a No. 2 or No. 3 catheter, can be separated by thrusting between them a segment of a cone fixed to a slender stem. This cone or olive separates the blades till they occupy a space equal to No. 12 , this to a No. 14, and this to No. 16, of Weiss's catheter-scale.

In using the instrument, I first explore the urethra with an oliveheaded graduated bougie, to ascertain the position of the stricture. I then introduce the dilator with the blades approximated until this portion, which is bluntly knife-edged, lies in the stricture. The cone is next passed down between the blades, and bursts the stricture with very little force. The largest cone produces slight laceration of the meatus, which is of no moment, or that may be previously incised ; but it has no injurious effect upon the elastic healthy part of the urethra.

The advantages which I anticipate will be found to belong to this dilator are, first, simplicity and cheapness of construction. The numerous parts of Holt's instrument raise the cost to nearly three guineas; while I am informed by Mir. Coxeter, who has very ingeniously carried out my ideas, that this can be made for a guinea and a half, if not for less.

Read in the Surgical Section at the Annual Meeting of the British Medical Association in Plymouth, August $187 \mathrm{r}$. 
Again, the central guide of Holt's instrument is not needed in mine : hence this split sound can be passed through narrower strictures. It is true that, by doing away with the central guide, we lose Smyly's addition of a catheter to the dilator, whereby an unskilful operator may be satisfied that he has kept the true path to the bladder, and not diverged into a false passage. But this advantage is not practically a great one in'actual use. The fine tube often gets blocked by mucus; and the operator seldom needs to see the urine flow to be assured he has passed through, and not by the side of, a stricture.

The third and chief advantage is this-diminution of resistance. The force needed for Holt's dilator is sometimes very great ; indeed, I have seen his instrument break in the most skilful hands from this cause. Much of the power is required to overcome the continuous friction of the tube, both inside along the guide and outside on each half of the split sound. It is true that the necessity for excessive force has been overcome by screwing down the dilating tube; but what seems to me a very important point in Holt's plan of treatment is thus lost-namely, rapidity. The slowness of a screw fails to completely break through all the indurated tissue : part is only stretched, and soon contract again. In the dilator before you, the friction-surface is reduced to these two dovetail grooves, which together do not measure more than half an inch. The rapid application of the wedge to the stricture is obtained by a force so small, that one hand has hitherto sufficed to overcome the resistance.

It is not my intention to occupy your time in discussing the relative merits of treating stricture by suddenly breaking through the patch of induration which causes it, and of slowly dilating by repeated passage of bougies. This question has been recently debated by the profession. Mr. Holt's plan is proved and acknowledged to be a safe, easy, and speedy mode of treatment. There are, however, two points which have not yet, so far as I am aware, been much insisted upon. Nevertheless, I am supported in my opinion by that of my teacher and colleague Sir Henry Thompson. Rupturing the tissue is not applicable to penile strictures or those anterior to the bulb. Here incision is preferable, because the new matter abundantly produced to repair the rent often blocks up the spongy tissue so much as to prevent or impede erection beyond the point ruptured. A clean internal incision does not cause the same amount of plastic formation, and hence subsequent erection is not interfered with after this mode of division.

The second point is this: No. 12 is rarely large enough to split all the fibres of a stricture; some are only stretched, and contraction returns as soon as after gradual dilatation. Hence I have carried the size of the cone to Nu. 16 for urethras where the calibre naturally approaches No. 10 and No. 12.

The instrument is only just out of the maker's hands ; hence my experience is limited to four cases, in all of which the urethra has been fully dilated; the patients have had no bad symptoms whatever, and they have been detained in bed only a few hours.

CASE I. - M., aged 28, was admitted to University College Hospit al July 15th, 1871. Difficulty in passing urine had been noticed three months. A No. 4 olive bougie stopped at six inches. The dilator with No. I4 cone was passed under chloroform. The stricture yielded at once. There was pretty free hæmorrhage. No instrument was introduced after the dilator was withdrawn. On July I6th, urine had passed very well the previous night, and the patient slept all night without any opiate. On July I8th, I passed a No. 12 probe-ended catheter, and drew off the urine. He attends twice weekly to have a bougie passed, until he can pass one himself.

CASE II.- J., aged 3I, a horsekeeper, was admitted to University College Hospital July 2oth, 187 I. Difficulty in passing his urine had been felt for twelve years, and the patient had several times been relieved of retention at this hospital. At $4 \frac{3}{4}$ inches, a stricture was found, through which, after some difficulty, a filiform bougie, about No. $\frac{1}{4}$ in size, was passed and tied in. For micturition, the patient was twice compelled to withdraw the bougie, but replaced it himself. On the 2Ist, a s catheter was passed and tied in. On the 24th, the dilator was passed with the No. 16 cone. Very little hæmorrhage took place, and by a No. 13 catheter the urine was drawn off. On the 26 th, the No. 13 catheter was easily introduced, and the patient is now learning to pass his own instrument regularly.

CASE 1II.-August 27th. A gentleman since 1867 had kept his stricture dilated by the occasional passage of No. Io and I I bougies. Notwithstanding this, an abscess ending in perineal fistula formed in 1870, which apparently healed, to break open again with abscess three times, though the patient had been careful after each abscess to draw off his urine regularly through a catheter. This being his third attack, the patient begged me to do something to prevent its recurrence; and on August 2nd, Dr. Squarey giving chloroform, I burst the stricture by the No. 16 cone, and passed afterwards a 16 pewter sound to the blad- dex. No bad symptom occurred. There was very little pain in passing urine the first time; none after that. No. 13 passed easily on August $4^{\text {th }}$ and 6 th.

\section{ON THE PHYSICAL GEOGRAPHY AND CLIMATE OF SPAIN, AND OF ITS HEALTH-RESORTS.*}

By JAMES HENRY BENNET, M.D., Late Obstetric Physician to the Royal Free Hospital, London.

IN order to understand the climate of Spain, it is absolutely necessary to be acquainted with its physical geography. The peninsula of Spain is constituted by a plateau or table-land, upraised some two thousand or more feet above the sea, and intersected from east to west by a series of mountain ranges all but parallel to the Pyrenees. The principal of these mountain ranges are the Sierra Guadarrama, the Sierra Toledo, the Sierra Morena, and the Sierra Nevada. The table-lands between these ranges were formerly the beds of seas, of estuaries, and of fresh-water lakes, and are now traversed by rivers, in a direction parallel to the mountain ridges, which empty themselves into the Atlantic or Mediterranean. All the larger rivers, with the exception of the Ebro, direct their course to the Atlantic.

The main mountain chains of Spain are of primary formation, and constitute the basis of its geology. They emerged beiore the secondary strata which surround them, and are formed of granite, gneiss, crystalline schists, etc. Secondary rocks, represented by the trias triple, and also by the jurassic and cretaceous formations, occupy a vast area in the eastern and southern regions of Spain. In the table-lands, plains, and river-valleys, are found tertiaries, old and recent, nummulitic rocks, as also miocene and pliocene formations. Fresh-water miocene fossils are found at an elevation of two thousand five hundred feet, which shows how greatly the peninsula of Spain must have been raised in comparatively recent geological times.

Below this central table-land of Spain is the coast, sometimes a mere ledge or undercliff, like the Undercliff in the Isle of Wight, or the Genoese Riviera, but often presenting small alluvial plains of greater or less width, watered by rivers that descend from the mountains, and from the elevated plains of the interior.

Thus, Spain may be compared familiarly to a square dining-room table, with a narrow ledge of coast on the floor. Of course the climate of the upraised mountainous table-land, and that of the subjacent coast, must be, and are, very different. Although Spain lies far south, between the thirtieth and the forty-fourth degrees of latitude, an elevation of two or three thousand feet does not protect its interior from intense scorching heat in summer. The city of Madrid, which is two thousand seven hundred feet above the sea, in midsummer is one of the hottest and most burnt up cities in southern Europe. But this altitude, combined with the parallel chains of huge snow-covered mountains, gives in winter to central Spain nearly as low a temperature as that of northern Europe. That such is the case is evidenced by the vegetation, which is not more southern than the vegetation of the less favoured regions of England.

The coast-line, especially the south-eastern coast-line, presents very different physical conditions. Bathed by the warm Mediterranean Sea, exposed in full to the powerful south-eastern sun, protected from the north north-west and south-west winds by the entire bulk of the mountain land of Spain, it is really a southern region, as its vegetation testifies. There are other influences which e eij to modify its climate. It is all but a rainless tract, and certainly the driest region in Europe. I have never met with a thoroughly satisfactory explanation of this fact, which most observers and writers announce without trying to explain. I was in Spain in May 1868, and previously to entering that country I had carefully explored Algeria, from Fort Napoleon in the east to Oran in the west, and from Algiers to the margin of the Desert of Sahara. The meteorological conditions there existing and recognised gave me, I believe, the key to this paucity of rain on the east coast of Spain.

The presence of the Pyrenees and of the mountain chains of central Spain at once explain the absence of rain on the eastern coast, with north, north-west, and even south-west winds. The rain-clouds are arrested in passing over these elevated regions, and their moisture is squeezed out. But why should not the north-east and south-east winds, which so frequently reign in the Mediterranean, and which pass over vast tracts of water before they reach the east coast of Spain, bring their burden of rain to the mountain-fringed shores of Spain? I be-

* Read before the Public Medicine Section at the Annual Meeting of the British Medical Association in Plymouth, August $187 \mathrm{r}$. 